\title{
Cableless In-piping Magnetic Actuator for Transportation over Long-range
}

\author{
Tomohiro Izumikawa ${ }^{1}$, Ryuichi Watanabe ${ }^{1} \&$ Hiroyuki Yaguchi $^{1}$ \\ ${ }^{1}$ Faculty of Engineering, Tohoku Gakuin University, Miyagi, Japan \\ Correspondence: Hiroyuki Yaguchi, Faculty of Engineering, Tohoku Gakuin University, 1-13-1 Chuo, Tagajo, \\ Miyagi, Japan. Tel: 81-223-687-104. E-mail: yaguchi@mail.tohoku-gakuin.ac.jp
}

Received: July 14, 2015 Accepted: September 22, 2015 Online Published: October 13, 2015

doi:10.5539/mer.v5n2p37 URL: http://dx.doi.org/10.5539/mer.v5n2p37

\begin{abstract}
This paper proposes a cableless In-piping magnetic actuator capable of locomotion over long range of 1,000 m within a pipe having an inner diameter of $10 \mathrm{~mm}$. The cableless magnetic actuator is moved by using resonance energy of a mass-spring system excited by using an electromagnetic force. The proposed actuator incorporates a new type of an electrical inverter that directly transforms DC from button batteries into AC. The electrical DC-AC inverter incorporates a mass-spring system, two reed switches and two curved permanent magnets that switch under an electromagnetic force. The conventional DC-AC inverter and the newly proposed inverter were compared, and the effect of the inverter on the motive properties of the cableless magnetic actuator was examined. The influence of the consumption current of the battery on the range of the actuator was examined. Experimental result demonstrates that the cableless magnetic actuator was able to move horizontally at $1,588 \mathrm{~m}$, and horizontal speed at $176.5 \mathrm{~mm} / \mathrm{s}$ when two reed switches were used.
\end{abstract}

Keywords: cableless actuator, electrical DC-AC inverter, pipe inside mover, new motion principle, locomotion

\section{Introduction}

The demand of in-piping robot to transport a medicine and bacteria from a laboratory to a laboratory in the same building or another building is increasing. Safety and shortening of the transportation time increases by using a pipe transportation method. By this approach, the inside air of the pipe is completely intercepted with outside air. If an accident occurs in the pipe, we can evade a situation scattering hazardous materials such as virus outside a pipe. However, the realization for in-piping cableless robots capable of locomotion over long range inside the pipe is required. A many studies have investigated the mechanisms of an actuator having an attached electrical cable to provide locomotion in the pipe using devices such as piezoelectric elements (Saito et al., 2000; Fujita et al., 2004), air cylinders (Ohno et al., 2006), shape memory alloys (Reynaerts et al., 1996; Kwon et al., 2005), and electromagnetic motors (Choi et al., 2007; Miyagawa et al., 2008; Bocko et al., 2009). There are several potential problems in the design, however, with regard to extending the range and avoiding tangling of the electrical cable, and thus it is clearly desirable to adopt a cable-free system. However, little research has been conducted on cableless robots (Fukuda et al., 1991; Tsuruta et al., 2002) and electromagnetic vibration type (Yaguchi et al., 2009; Yaguchi et al., 2011; Izumikawa et al., 2012) proposed by authors. Experiment results were compared to analytical results and the validity of the novel motion principle was completely verified (Yaguchi et al., 2013). In addition, the additional devices of a CCD camera, two LED lights, a transmitter with a wire antenna, and various types of batteries were attached to the proposed cableless magnetic actuator system. The inspection range of this actuator system was a horizontal distance of $402 \mathrm{~m}$ and a vertical motion of $261 \mathrm{~m}$ for over 50 minutes (Yaguchi et al., 2014) proposed by authors.

The actuator is moved due to mechanical resonance energy of the mass-spring system produced by an electromagnetic force. In-piping cableless actuators are not capable of movement over long range of 1,000 m.

This paper proposes a novel cableless magnetic actuator system with a new type of electrical DC-AC inverter that is coupled to two reed switches and two permanent magnets. The waveform of the interchange is generated by a DC battery, and the technique used to drive the cableless actuator is demonstrated. We compare the conventional DC-AC inverter and the newly proposed inverter, and examine the effect of the inverter on the motive properties of the cableless actuator. A driving test of the cableless actuator capable of movement inside a 
pipe having an inner diameter of $10 \mathrm{~mm}$ was carried out. Additionally, the influence of the consumption current of the battery on the range of the actuator was examined. Experimental results demonstrated that the total range of the cableless actuator was more than $1,000 \mathrm{~m}$. The results hold great promise for the creation of highly mobile actuators capable of moving in pipes with diameters of under $10 \mathrm{~mm}$.
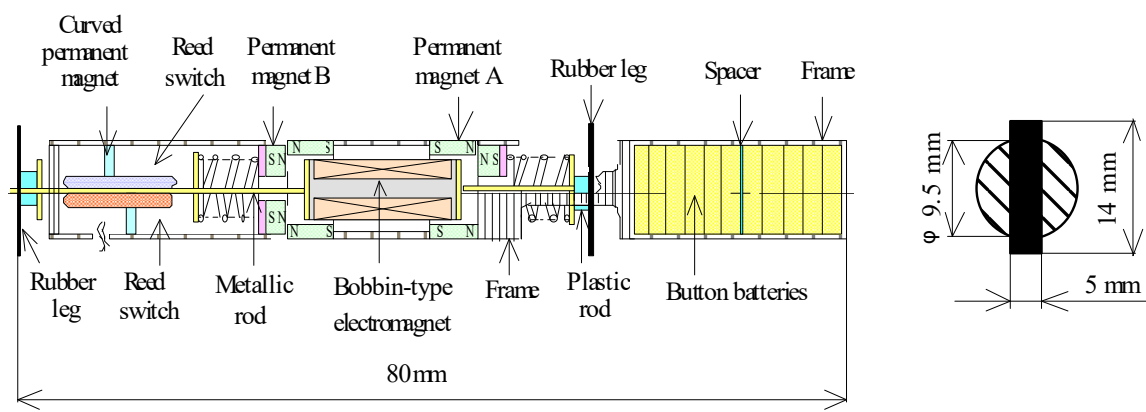

Figure 1. Structure of the cableless magnetic actuator

\section{Structure of the Cableless Magnetic Actuator}

Figure 1 shows a diagram of the proposed cableless magnetic actuator, which is capable of moving within a pipe having an inner diameter of $10 \mathrm{~mm}$. The cableless actuator consists of a propulsion module, an electrical DC-AC inverter composed of two reed switches and two curved permanent magnets, a frame, and a ten button batteries. The propulsion module is composed of two identical ring-type permanent magnets, labeled $\mathrm{A}$ and $\mathrm{B}$, two translational springs, two metallic rods with plastic circular plates, and a bobbin-type electromagnet. Permanent magnets $\mathrm{A}$ and $\mathrm{B}$ are $\mathrm{NdFeB}$ magnets and are magnetized in the axial direction. Permanent magnet $\mathrm{A}$ has an outer diameter of $7.8 \mathrm{~mm}$, an inner diameter of $5.8 \mathrm{~mm}$, and a thickness of $2.5 \mathrm{~mm}$. Permanent magnet $\mathrm{B}$ has an outer diameter of $6.5 \mathrm{~mm}$, an inner diameter of $2 \mathrm{~mm}$, and a thickness of $1.5 \mathrm{~mm}$. The two identical translational springs are stainless steel compression-coil-type springs and have an outer diameter of $5.5 \mathrm{~mm}$, a free length of $6.5 \mathrm{~mm}$, and a spring constant of $\mathrm{k}=2,400 \mathrm{~N} / \mathrm{m}$. The bobbin-type electromagnet consists of an iron core with 3,200 turns of $0.07-\mathrm{mm}$-diameter copper wire. The electrical resistance of the electromagnet is $225 \Omega$. The legs used to support the actuator are constructed of natural rubber and have a total length of $10 \mathrm{~mm}$, a thickness of 0.5 $\mathrm{mm}$, and width of $5 \mathrm{~mm}$. The actuator which contains ten batteries has a length of $80 \mathrm{~mm}$ and a total mass $\mathrm{M}_{\mathrm{a}}$ of $12 \mathrm{~g}$. The magnetic actuator is able to move by the difference in frictional force between forward and backward supporting force of the natural rubber Yaguchi et al. (2013).

\section{Principle of the DC-AC Inverter}

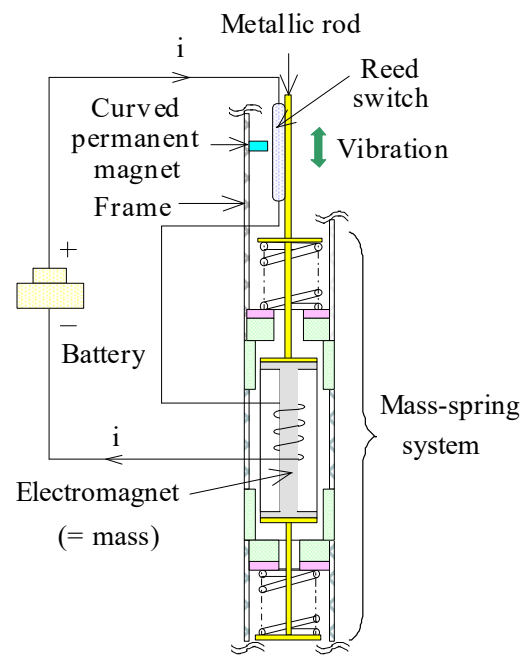

(a) One reed switch

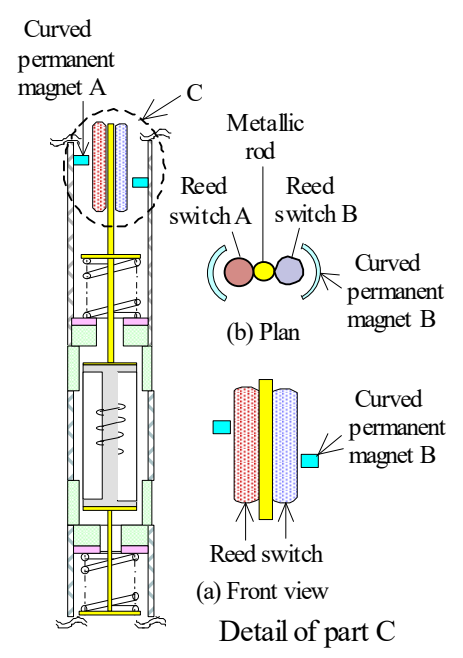

(b) Two reed switches

Figure 2. Principle of the electrical DC-AC inverter 
Figure 2(a) illustrates the principle of the electrical DC-AC inverter proposed in the previous paper (Yaguchi et al., 2011; Izumikawa et al., 2012; Yaguchi et al., 2013), which was developed in order to realize a cableless magnetic actuator. Figure 2(b) illustrates the principle of the proposed electrical DC-AC inverter. The proposed inverter is composed of two reed switches and two curved permanent magnets. Each reed switch has a diameter of $1.8 \mathrm{~mm}$ and a length of $10 \mathrm{~mm}$. The two curved permanent magnets, A and B, are arc type NdFeB magnets having a width of $1 \mathrm{~mm}$ and a thickness of $1 \mathrm{~mm}$ and are magnetized in the axial direction. In the experiment, ten button batteries were divided into two packs by five packages.
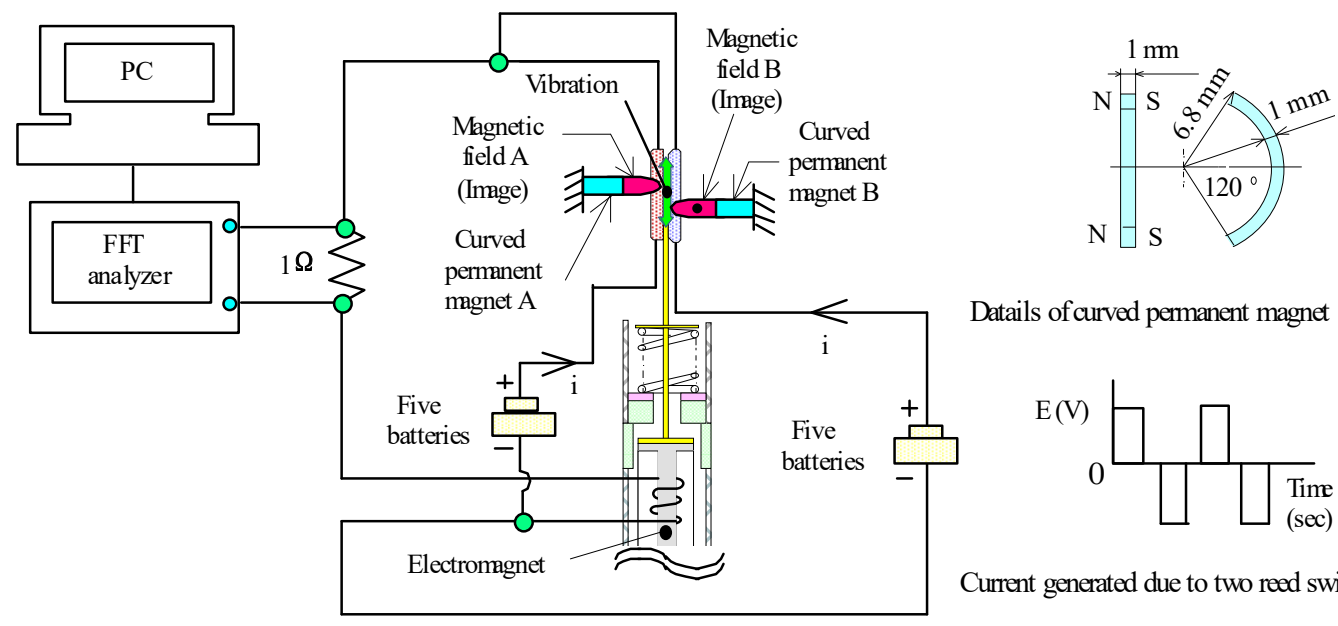

Datails of curved permanent magnet

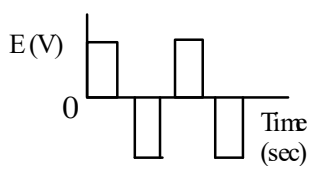

Current generated due to two reed switches

Figure 3. Concept of the AC-DC inverter

Figure 3 shows the connection of an electrical wire and the concept of the electrical DC-AC inverter using two reed switches. Such a connection generates an alternating current waveform from the DC battery. Reed switch A and $\mathrm{B}$ attached to the electromagnet vibrates around two curved permanent magnets I and II, respectively. The two curved permanent magnets, I and II, are arc type NdFeB magnets having a width of $1 \mathrm{~mm}$ and a thickness of $1 \mathrm{~mm}$ and are magnetized in the axial direction. The magnetic field between the reed switch and the curved permanent magnet is changed. The two cantilever beams inserted into each reed switch make and break contact as the switch is cycled on and off. As a result, the DC voltage is converted into a square alternating current waveform, and the resulting magnetic force acts on the mass-spring system. The on-areas of reed switch A and B, and the off-areas of switch A and B indicated in previous study (Yaguchi et al., 2014). The DC source for the experiment was two packs of five button batteries. When the electromagnet was connected to two battery packs, the direct current into the electromagnet was $0.05 \mathrm{~A}$. The current waveform generated during switching of the reed switch was stored in a personal computer (PC) via a fast Fourier transform (FFT) analyzer as shown in Figure 3.

\section{Locomotion Characteristics}

Figure 4 shows photograph of this cableless actuator and an experimental apparatus. The cableless actuator was inserted in an acrylic pipe of $10 \mathrm{~mm}$ inside diameter. Two coil A and B were placed outside of an acrylic pipe. The movement speed of the cableless actuator was measured by the time lag between two coils by using FFT analyzer. Maxell SR920W silver-oxide button batteries were used to drive the propulsion module of the cableless magnetic actuator. Each battery is $9.5 \mathrm{~mm}$ in diameter and has a mass of $0.6 \mathrm{~g}$ and a capacity of $39 \mathrm{mAh}$ at a nominal output of $1.55 \mathrm{~V}$. The supporting force of the actuator in the pipe was set to $0.12 \mathrm{~N}$.

The solid line in Figure 5 shows the relationship between the number of button batteries and the vertical upward speed of the actuator when two reed switches were loaded in the cableless actuator. For the cases of ten batteries and six batteries, the vertical upward speeds were $121 \mathrm{~mm} / \mathrm{s}$ and $40 \mathrm{~mm} / \mathrm{s}$, respectively. In this figure, the broken line indicates the results for one reed switch. When powered by ten batteries, the maximum vertical speed was $225 \mathrm{~mm} / \mathrm{s}$ as shown in previous study (Yaguchi et al., 2014).

The solid line in Figure 6 shows the relationship between the tilt angle $\alpha$ and the speed of the actuator using ten button batteries when two reed switches were loaded. Ten button batteries were divided into two packs as shown 
in Figure 3. The tilt angle was varied from $\alpha=-90^{\circ}$ (straight downward) to $\alpha=90^{\circ}$ (straight upward). The broken line shows the results for one reed switch when ten batteries were used.

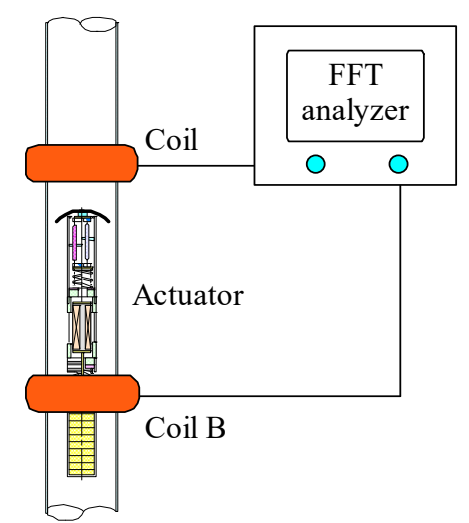

Acrylic pipe

(a) Experimental apparatus

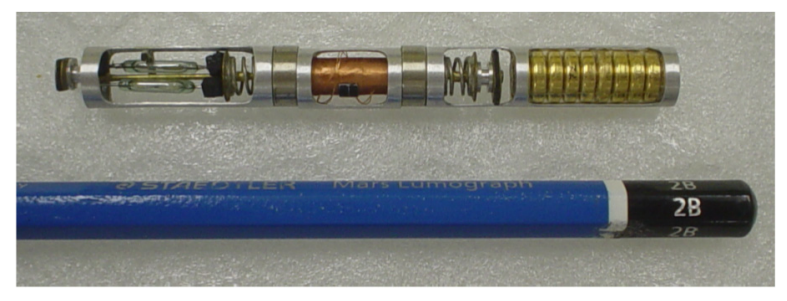

(b) Photograph of the cableless actuator

Figure 4. Experimental apparatus and cableless actuator

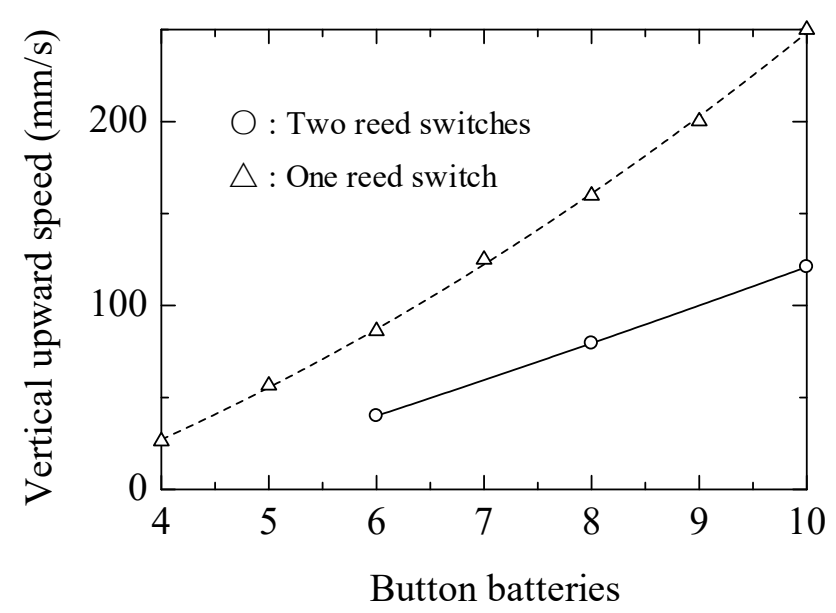

Figure 5. Relationship between number of batteries and vertical upward speed
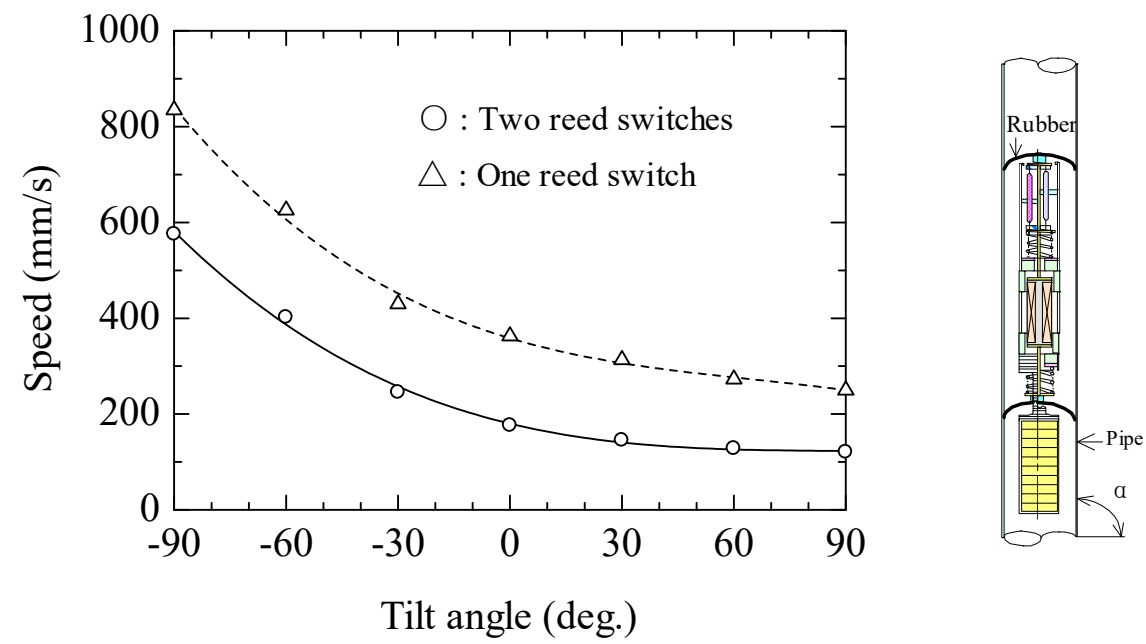

Figure 6. Relationship between tilt angle $\alpha$ and speed. 
The solid line in Figure 7 shows the relationship between the load mass and the vertical upward speed of the actuator for ten button batteries. The figure indicates that the actuator can climb upward at $43.5 \mathrm{~mm} / \mathrm{s}$ when pulling a load mass of $10 \mathrm{~g}$, which is a moderately high performance. In this figure, the broken line shows the results for one reed switch as shown in previous paper (Yaguchi et al., 2014). The average of the consumption current in the case of one reed switch was $18 \mathrm{~mA}$. However, that of two reed switches was $13 \mathrm{~mA}$. Accordingly, the average of the consumption current by using five button batteries becomes $6.5 \mathrm{~mA}$. This cableless actuator can move by a little consumption current.

Figure 8 shows the relationship between the load mass and self-propellant efficiency of the actuator for ten batteries. The self-propellant efficiency is expressed as follows:

$$
\eta[\%]=\frac{\left(M_{a}+M_{L}\right) v_{u p} \times G}{V \times I} \times 100
$$

where $M_{a}$ is the total mass of the cableless actuator, $M_{L}$ is the load mass, $v_{u p}$ is the vertical speed, $G$ is the acceleration due to gravity, $\mathrm{V}$ is the input voltage and $\mathrm{I}$ is average of the consumption current. The maximum efficiency is $34 \%$ for ten batteries when two reed switches were loaded. The maximum efficiency is thought to be high for an electromagnetic actuator of this size. The broken line in Figure 8 shows the results when one reed switch was loaded.

Figure 9 shows the relationship between the consumption current and the life of the button battery. If there are many consumption currents, the time of battery life drops sharply. It is approximated by the fifth-order equation of battery life time $\mathrm{t}$ minutes when I $\mathrm{mA}$ is input current into the actuator.

$$
\mathrm{t}(\min )=517.51-99.71 \times \mathrm{I}+8.95 \times \mathrm{I}^{2}-0.411 \times \mathrm{I}^{3}+9.31 \times 10^{-3} \times \mathrm{I}^{4}-8.31 \times 10^{-5} \times \mathrm{I}^{5}
$$

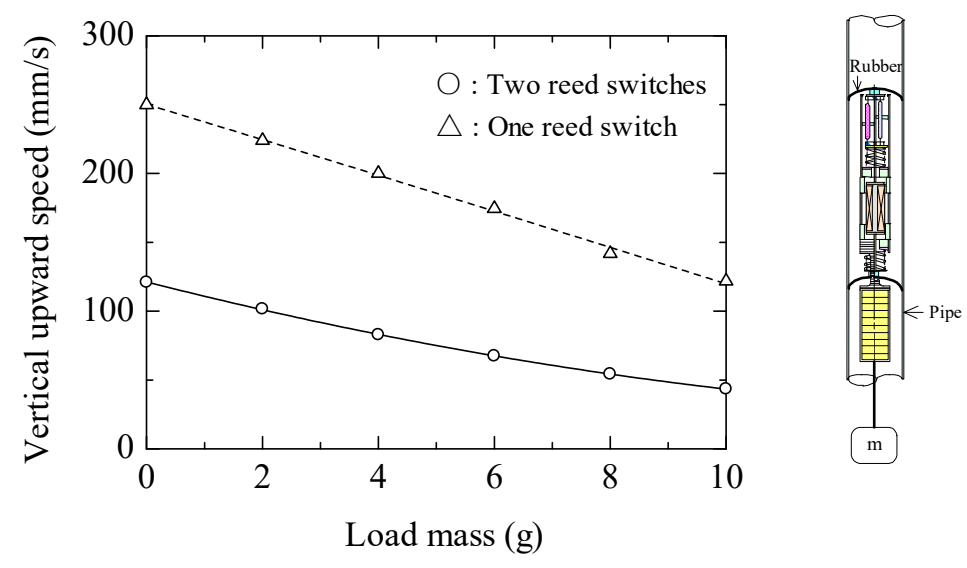

Figure 7. Relationship between load mass and vertical upward speed

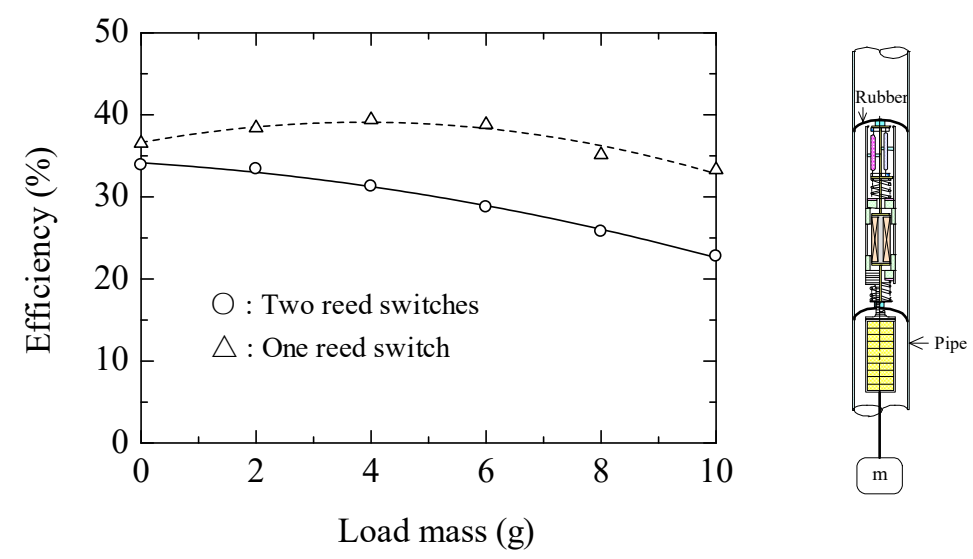

Figure 8. Relationship between load mass and efficiency. 


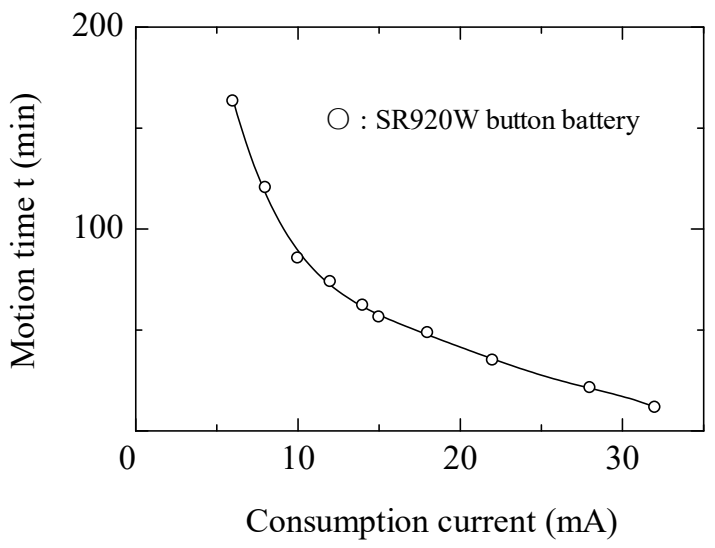

Figure 9. Relationship between consumption current and continuous motion time.

Table 1. Continuous motion time and range (The case of one reed switch)

\begin{tabular}{lllll}
\hline Number & Consumption & Vertical & Time & Range \\
\hline of batteries & current $(\mathrm{mA})$ & speed $(\mathrm{mm} / \mathrm{s})$ & $(\mathrm{min})$ & $(\mathrm{m})$ \\
4 & 8 & 26.3 & 117 & 184 \\
5 & 10 & 56.6 & 89 & 302 \\
6 & 12 & 86.2 & 72 & 372 \\
7 & 14 & 125 & 61 & 457 \\
8 & 15 & 159.8 & 57 & 546 \\
9 & 16.5 & 200.2 & 52 & 624 \\
10 & 18 & 250 & 47 & 705 \\
\hline
\end{tabular}

Table 2. Continuous motion time and range (The case of two reed switches)

\begin{tabular}{lllll}
\hline Number & Consumption & Vertical & Time & Range \\
\hline of batteries & current $(\mathrm{mA})$ & speed $(\mathrm{mm} / \mathrm{s})$ & $(\mathrm{min})$ & $(\mathrm{m})$ \\
6 & 4 & 40 & 237 & 568 \\
8 & 5.5 & 79.5 & 178 & 849 \\
10 & 6.5 & 121 & 150 & 1089 \\
\hline
\end{tabular}

Table 3. Continuous motion time and range (The case of two reed switches)

\begin{tabular}{lllll}
\hline $\begin{array}{l}\text { Number } \\
\text { of batteries }\end{array}$ & $\begin{array}{l}\text { Consumption } \\
\text { current }(\mathrm{mA})\end{array}$ & $\begin{array}{l}\text { Horizontal } \\
\text { speed }(\mathrm{mm} / \mathrm{s})\end{array}$ & $\begin{array}{l}\text { Time } \\
(\mathrm{min})\end{array}$ & $\begin{array}{l}\text { Range } \\
(\mathrm{m})\end{array}$ \\
\hline 10 & 6.5 & 176.5 & 150 & 1588 \\
\hline
\end{tabular}

Table 1 shows the continuous motion time and range when one reed switch was loaded in the actuator. The maximum range of this cableless actuator was $765 \mathrm{~m}$ for vertical motion over 51 minutes when powered by 10 button batteries with no load mass.

Table 2 and Table 3 show the continuous motion time and range when two reed switches were loaded in the cableless actuator with no load mass. For vertical direction, this cableless actuator can move range of 1,089 m. On the other hand, that at horizontal direction was $1,588 \mathrm{~m}$. The moving speed is lower than one reed switch type, however two reed switches type is capable of movement over long range of 1,000 m.

Figure 10 shows the relationship between the consumption current and total range at vertical upward direction of the cableless actuator. When the consumption current is small, the battery life is prolonged drastically. 


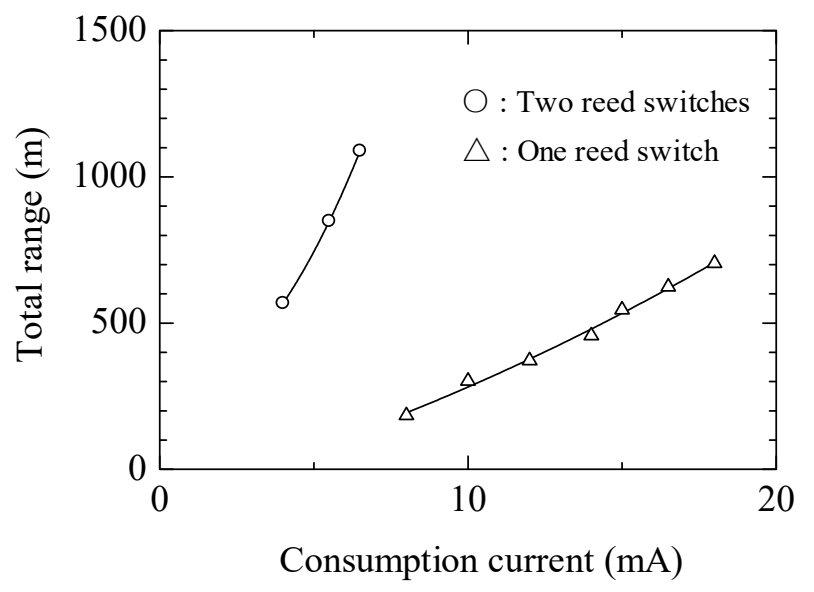

Figure 10. Relationship between total range and consumption current

\section{Conclusion}

A cableless magnetic actuator with a new electrical DC-AC inverter has been proposed. When powered by two battery packs of button batteries using two reed switches, the cableless actuator displayed speeds of $575.9 \mathrm{~mm} / \mathrm{s}$ moving vertical downward, $176.5 \mathrm{~mm} / \mathrm{s}$ moving horizontally, and $121 \mathrm{~mm} / \mathrm{s}$ moving vertical upward. Since it moves downward much more quickly than it climbs, the actuator must be lightened to eliminate this large disparity. Experimental results demonstrated that the cableless actuator was found to be fully applicable to locomotion in a thin pipe.

The total operating range of this cableless magnetic actuator is $1,588 \mathrm{~m}$ in the horizontal direction or $1,089 \mathrm{~m}$ in the vertical direction over an operating time of 150 min when powered by two battery packs. The moving speed is lower than one reed switch model, however the actuator of two reed switches type is capable of movement over long range of $1,000 \mathrm{~m}$. On the otherhand, the maximum efficiency is $34 \%$ when two reed switches were loaded. The maximum efficiency is thought to be high for an electromagnetic actuator of this size.

If the power requirement of the propulsion module can be lowered, it appears possible to extend the range of the actuator to five kilometer. In the future, the magnetic circuit of the proplusion module for the actuator and the connection of the actuator body will be improved. Future research will be directed toward these goals.

\section{References}

Saito, H., Sato, K., Kudo, K., \& Sato, K. (2000). Fundamental Study of Mover Travel inside a Small Diameter Pipe. Trans. Japan Soc. Mec. Eng., 66(641), 346-353.

Fujita, S., Shiraogawa, Y., Yamamoto, S., \& Kato, T. (2004). Study of mobile mechanism with elastic fibers by using vibration. Trans. Japan Soc. Mec. Eng., 70(698), 22-26.

Ohno, M., Hamano, T., \& Kato, S. (2006). Modeling and fabrication of a mobile inspection microrobot driven by a pneumatic bellows actuator for long pipes. Journal of Robotics and Mechatoronics, 18(1), 11-17.

Kwon, J., Park, S., Kim, B., \& Park, J. O. (2005). Bio-material property measurement system for locomotive mechanism in gastro-intestinal tract. In Robotics and Automation, 2005. ICRA 2005. Proceedings of the 2005 IEEE International Conference on (pp. 1303-1308). IEEE.

Reynaerts, D., Peirs, J., \& Van Brussel, H. (1996). Design of a shape memory actuated gastrointestinal intervention system. Proc. Actuator, 96.

Miyagawa, T., \& Iwatsuki, N. (2008). Moving characteristics in bent pipes of in-pipe mobile robot with wheel drive mechanism using planetary gear drive. Journal of the Japan Society for Precision Engineering, 74(12), 1346-1350.

Bocko, J., Kelemen, M., Kelemenova, T., \& Jezný, J. (2009). Wheeled locomotion inside pipe. Bulletin of applied mechanics, 5(18), 34-36.

Choi, H. R., \& Roh, S. G. (2007). In-pipe robot with active steering capability for moving inside of pipelines. Bioinspiration and Robotics Walking and Climbing Robots, 23, 375-400. 
Fukuda, T., Hosoi, H., \& Ohyama, H. (1991). A Study on In-Pipe Inspection Robots. Trans. Japan Soc. Mec. Eng., 57(537), 243-7248.

Tsuruta, K., Shibata, T., Mitsumoto, N., Sasaya, T., \& Kawahara, M. (2002). Compact and low power consumed control circuit for wireless micromachine. Transactions of the Institute of Electric Engineers of Japan, 122(2), 67-72.

Yaguchi, H., Ishikawa, K., \& Zanma, T. (2009). A novel cableless magnetic actuator capable of reversible motion in a thin pipe. Magnetics, IEEE Transactions on, 45(10), 4530-4533.

Yaguchi, H., \& Izumikawa, T. (2011). Cableless magnetic actuator capable of locomotion in a thin pipe by means of a new motion principle. Magnetics, IEEE Transactions on, 47(10), 4290-4293.

Izumikawa, T., \& Yaguchi, H. (2012). Movement of a cableless in-piping magnetic actuator with a new propulsion module. Magnetics, IEEE Transactions on, 48(11), 4196-4199.

Yaguchi, H., \& Izumikawa, T. (2013). Wireless in-piping actuator capable of high-speed locomotion by a new motion principle. Mechatronics, IEEE/ASME Transactions on, 18(4), 1367-1376.

Yaguchi, H., \& Izumikawa, T. (2014). Cableless In-piping Magnetic Actuator System Capable of Inspection Over Long Distances. Magnetics, IEEE Transactions on, 50(11), 1-4.

\section{Copyrights}

Copyright for this article is retained by the author(s), with first publication rights granted to the journal.

This is an open-access article distributed under the terms and conditions of the Creative Commons Attribution license (http://creativecommons.org/licenses/by/3.0/). 